\title{
Geometric morphometric analysis of skull morphology reveals loss of phylogenetic signal at the generic level in extant lagomorphs (Mammalia: Lagomorpha)
}

\author{
Deyan $\mathrm{Ge}^{1}$, Lu Yao ${ }^{2}$, Lin Xia' ${ }^{1}$ Zhaoqun Zhang ${ }^{3}$, Qisen Yang ${ }^{1,4}$ \\ ${ }^{1}$ Key Laboratory of Zoological Systematics and Evolution, Institute of Zoology, Chinese Academy of Sciences, \\ Beichen West Road, Chaoyang District, Beijing 100101, China \\ ${ }^{2}$ Department of Anthropology, The Field Museum, Chicago, Illinois 60605, USA \\ ${ }^{3}$ Institute of Vertebrate Paleontology and Paleoanthropology, Chinese Academy of Sciences, Beijing 100044, China \\ ${ }^{4}$ Email: yangqs@ioz.ac.cn
}

Key words: centroid size, Leporidae, morphometry, Ochotonidae, phylogeny, skeletal features

\begin{abstract}
The intergeneric phylogeny of Lagomorpha had been controversial for a long time before a robust phylogeny was reconstructed based on seven nuclear and mitochondrial DNA sequences. However, skull morphology of several endemic genera remained poorly understood. The morphology of supraorbital processes in Lagomorpha is normally used as a diagnostic characteristic in taxonomy, but whether shape change of this structure parallels its genetic divergence has not been investigated. In this study, we conducted a comparative analysis of the skull morphology of all 12 extant genera using geometric morphometrics. These results indicated that no significant phylogenetic signal is observed in the shape change of the dorsal and ventral views of the cranium as well as in the lateral view of the mandible. The supraorbital processes also show insignificant phylogenetic signal in shape change. Similarly, mapping the centroid size (averaged by genus) of these datasets onto the phylogeny also showed insignificant phylogenetic signal. Aside from homoplasy caused by convergent evolution of skull shape, the massive extinction of lagomorphs after the late Miocene is proposed as one of the main causes for diluting phylogenetic signals in their morphological evolution. Acknowledging the loss of phylogenetic signals in skull shape and supraorbital processes of extant genera sheds new light on the long-standing difficulties for understanding higher-level systematics in Lagomorpha.
\end{abstract}

\section{Contents}

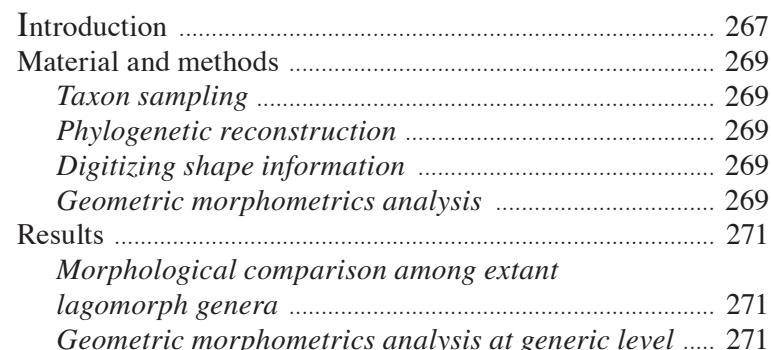

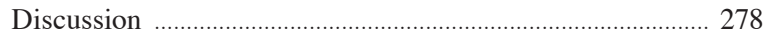

Phylogenetic signals in skull shape evolution of

lagomorphs at the generic level ...................................... 278

Morphological adaptation in the skull of lagomorphs .. 278

Acknowledgements .......................................................... 279

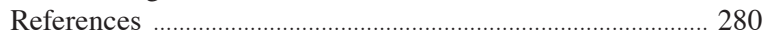

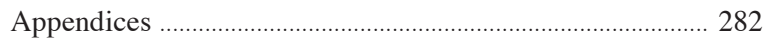

\section{Introduction}

Lagomorpha (rabbits, hares, and pikas) is one of the least diversified orders in mammals with only 12 extant genera (Hoffmann and Smith, 2005). Eight of these are monotypic taxa endemic to restricted areas and are poorly known. Among 92 extant species, three are critically endangered, ten are endangered, five are near threatened, five are vulnerable, and 31 others have a high probability for population decrease (The IUCN Red List of Threatened Species. Version 2014.3).

Besides the dynamics of genera or species diversity influenced by global vegetation change (Ge et al., 2013), the morphology of these herbivorous mammals also likely underwent adaptive evolution. For example, the body coloration of lagomorphs is inclined to match their habitats, and ear tip coloration appears to have a role in communication amongst congeneric species (Stoner et al., 2003). The crania of leporids are characterized by fenestration on the rostral side (Bramble, 1989), particularly in Lepus, which is beneficial for dynamic stability. Additionally, Lagomorpha tooth morphology reflects different mastication patterns: those of ochotonids demonstrate shearing ability while those of leporids favour grinding function (Koenigswald et al., 2010). As a result, the diets of these families are widely 

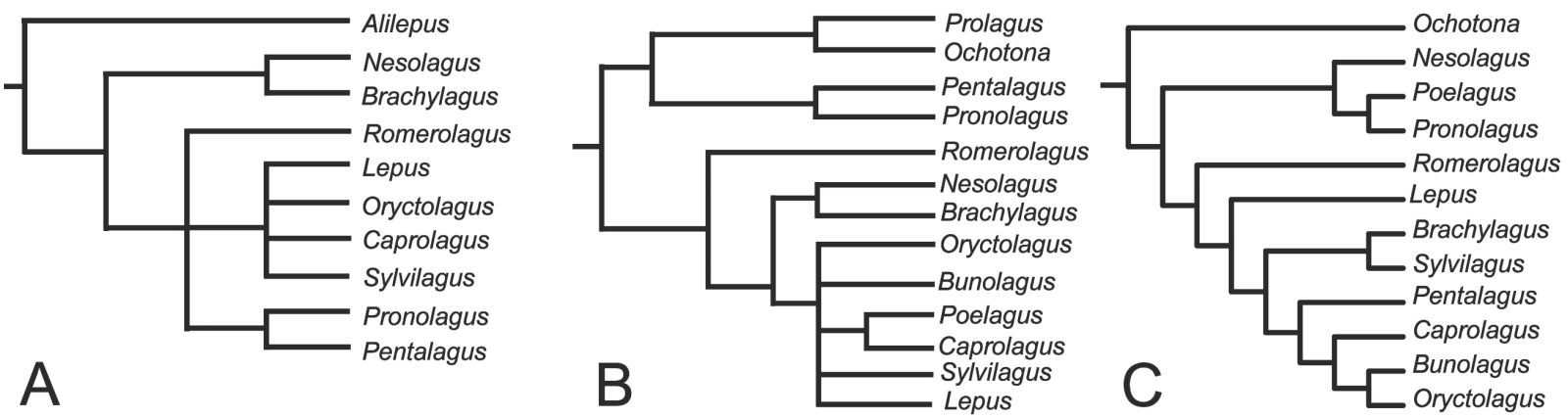

Fig. 1. Generic phylogenetic hypotheses of extant Lagomorpha. A. Adapted from Dawson 1981; B. Adapted from Stoner et al., 2003; C. Adapted from Matthee et al., 2004. Dawson (1981) proposed Nesolagus and Brachylagus as basal sister taxa and subdivided the other genera into three paraphyletic lineages (A). The first paraphyletic lineage includes Pronolagus and Pentalagus as sister taxa, the second lineage includes Lepus, Oryctolagus, Caprolagus and Sylvilagus, and the third is represented by Romerolagus. A weighted, phylogenetic supertree of all extant species of lagomorphs reconstructed using morphological and molecular data from 146 literature sources inferred a different phylogeny for lagomorphs (B): Prolagus (recently extinct) and Ochotona form a monophyletic group, Pentalagus and Pronolagus, consistent with Dawson's (1981) findings, are sister taxa, and the remaining genera from the Leporidae family form a monophyletic group. However, Oryctolagus, Bunolagus, Poelagus, Caprolagus, Sylvilagus and Lepus form a paraphyletic group (Stoner et al., 2003). Molecular phylogeny reconstructed from the concatenated dataset of seven genes (C) showing Ochotona, the genus that represents the relic genus of Ochotonidae, as the one that diverged earliest; Nesolagus, Poelagus and Pronolagus form a monophyletic clade that diverged early on within Leporidae, and the other clades of Leporidae include: Romerolagus, Lepus, Brachylagus, Slvilagus, Pentalagus, Caprolagus, Bunolagus, and Oryctolagus (Matthee et al., 2004).

differentiated. Ochotonids show a high preference for $\mathrm{C}_{3}$ plants while most leporids are capable of digesting $\mathrm{C}_{4}$ plants (Ge et al., 2013). The postcranial skeleton of Lepus has been reported to have prominent sutures, which is hypothesized to reduce jarring during high speed running (Bramble, 1989; Bramble and Carrier, 1983). The thoracic limb of the hare consists predominantly of extrinsic musculature with long parallel fascicles, which are specialized for generating a large range of forces (Williams et al., 2007). Ge et al., 2013 identified a significant correlation between the phylogeny and body length of extant species, but it is unclear how skull morphology of these taxa correlates with phylogeny. In fact, skull morphology of several endemic genera, aside from their tooth morphology (Averianov et al., 2000), still needs to be described and compared.

Within lagomorphs, the posterior supraorbital processes are well developed in most leporids (Bensley, 1948; Zhang, 1997), especially in several open grassland dwelling species, and some species also bear well-developed anterior supraorbital processes. However, in ancient taxa, both of these processes are nearly absent or poorly developed as seen in highly diversified Ochotonidae and stem lagomorph: Prolagus sardus, Alloptox gobiensis, Dawsonolagus antiquus, and Gomphos sp. (Dawson, 1969; Wu et al., 2003; Asher et al., 2005; Li et al., 2007; Wible, 2007). The morphology of these two structures has frequently been used as diagnostic characteristics in taxonomy (Luo, 1986; Suchentrunk et al., 2007; Zhang, 2010; Liu et al., 2011), but it is unclear whether the morphological evolution of this orbital region parallels the phylogenetic diversity of lagomorphs. So a detailed analysis of these structures is necessary.

Previous studies of morphological and ecological traits of extant lagomorph phylogeny resulted in different hypotheses (Fig. 1; Dowson, 1981; Stoner et al., 2003; Matthee et al., 2004; Robinson and Matthee, 2005). Considerable homoplasy in the morphology of leporid species was identified by Corbet (1983) after examining 21 morphological characteristics for 22 leporid species. These studies highlight the difficulties in reconstructing a robust Lagomorpha phylogeny, particularly at the intergeneric level by including morphological data. The phylogenetic relationship of extant genera was established from the combined matrix of five nuclear and two mitochondrial DNA fragments (Matthee et al., 2004). The robustness of this topology was highly supported by different methods in phylogenetic reconstruction, which offers a framework for more detailed phylogenetic comparative studies in Lagomorpha and allowed us to test whether there is a phylogenetic signal in their morphological evolution. 
In the present study, we applied geometric morphometrics to explore intergeneric morphological differences in the skull and to test the phylogenetic concordance of skull morphology changes (both size and shape) in extant Lagomorpha.

\section{Material and methods}

\section{Taxon sampling}

The crania of specimens used in the present study are preserved in the Institute of Zoology, Chinese Academy of Sciences (IOZCAS), the Northwest Institute of Plateau Biology, Chinese Academy of Sciences (NWIPBCAS), the Natural History Museum (NHM) in London, the Zoological Museum of Moscow State University (ZMMSU), the Zoological Institute of the Russian Academy of Sciences in Saint Petersburg (ZISP), the Museum of Comparative Zoology (MCZ) at Harvard University, the Field Museum of Natural History (FMNH), and the American Museum of Natural History (AMNH). Detailed information of these specimens is listed in Appendix 1.

A total of 87 adult specimens representing all 12 extant genera of Lagomorpha are included in the geometric morphometrics analyses. Adult specimens are identified by the presence of cranial suture fusion and the full eruption of the final molars. Previous studies based on skull morphology revealed that sexual dimorphism in lagomorphs is negligible (Smith and Weston, 1990; $\mathrm{Lu}, 2003$ ), which allows us to combine males and females in the analyses. Photographs used in this study were mainly taken using a Canon PowerShot S5IS (Japan) with a macro-focusing lens and then saved as JPEG files. A scale was set in each image using a ruler with centimetres as the unit of measure. Images were standardized for position, camera lens plane, and the distance between the camera lens and the specimen.

\section{Phylogenetic reconstruction}

We reconstructed a lagomorph phylogenetic tree based on Matthee et al.'s (2004) study, which appears to be the most robust and comprehensive study referring to the phylogeny of extant Lagomorpha. The resolved phylogeny was based on seven DNA fragments. Five of the seven DNA fragments were nuclear in origin: Stem cell factor (MGF), Thyroglobulin (TG), Protein Kinase $\mathrm{C}$ iota (PRKC1), B-spectrinnon erythrocytic 1 (SPTBN1), Thyrotropin (THY). The other two DNA fragments, Cytochrome b (cytb) and 12S rRNA (12S), are mitochondrial gene fragments. These sequences were aligned using ClustalW (Thompson et al., 2002) as implemented in MEGA version 5 (Tamura et al., 2007). 26 species of Lagomorpha were included, and Tamisciurus hudsonicus was used as the outgroup taxon. A best-fit model for nucleotide substitution of each gene was selected by using jModeltest (Posada, 2008). A MCMC Bayesian Analysis (Ronquist and Huelsenbeck, 2003) was performed for a concatenated dataset of the seven DNA sequences and unlinked substitution rates amongst the genes. Four chains with 200 million generations were set and sampled by a frequency of 1000 . The first $25 \%$ of the generated trees was discarded as burn-in. A 50\% majority consensus tree is obtained from the analysis. The resulting Bayes tree was provided in Appendix file S1.

\section{Digitizing shape information}

Using the photographs we selected and digitized 14 landmarks in the dorsal view of the cranium (DVC), 27 landmarks in the ventral view of the cranium (VVC), 25 landmarks in the lateral view of the mandible (LVM), and 50 landmarks in the upper edge along the orbit (UEAO) (Fig. 2). The morphology of supraorbital processes is an important character in traditional taxonomy of lagomorphs. To capture the detailed shape change of the UEAO (contour from landmark 6 to landmark 8 in Fig. 2A), we digitized a curve along the edge marked by 50 landmarks. The start point of this curve was located at the most anterior intersection point between the internal edge of the zygomatic and frontal bones (landmark 6) in the dorsal view, and the end point was located at the most posterior contour of the orbital process (landmark 8). These two end points could be easily recognized and digitized in all specimens. The other 48 points were located along the curves with equal lengths between adjacent points. The shape change of the UEAO results from the expansion of the lateral edge of the frontal bone (Yang, 1979), which provides homologous morphological information in the analysis. Definition of these landmarks is given in Appendix file 2. All landmark locations were defined and digitized in tpsDig Version 1.40 (Rohlf, 2002).

\section{Geometric morphometrics analysis}

A strong phylogenetic signal of shape change means that shapes of closely related taxa tend to be more similar to each other and thus occupy the same area of 

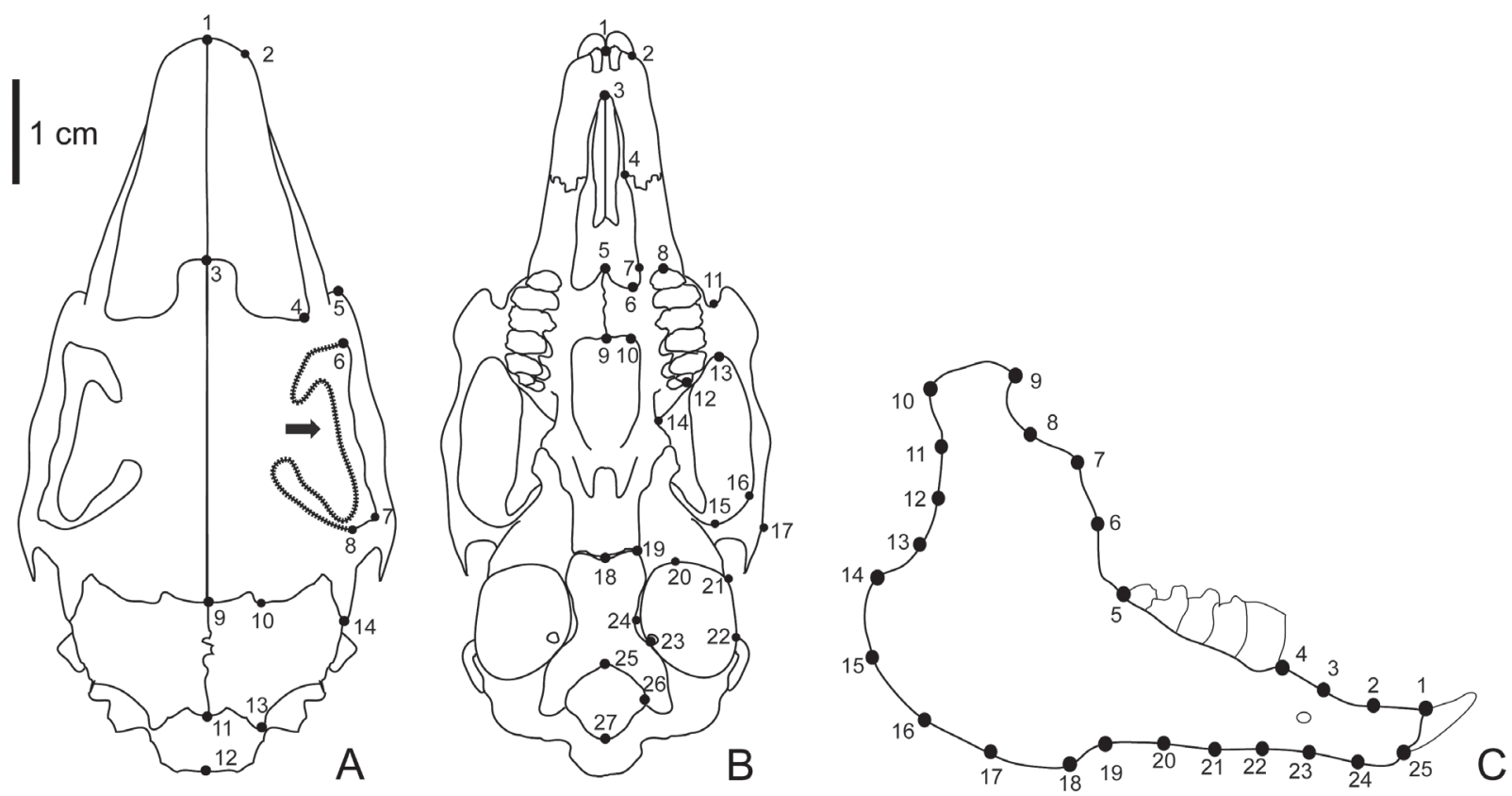

Fig. 2. Landmark locations. A. Dorsal view of the cranium. The arrow points to the location of the 50 landmarks on the upper edge along orbit (UEAO), which are highlighted by the dashed line. B. Ventral view of the cranium. C. Lateral view of the mandible.

morphometric space (Klingenberg and Gidaszewski, 2010). To test for phylogenetic signals in shape and size changes we applied squared-change parsimony under a Brownian motion model of evolution to reconstruct the ancestral states of shapes at internal nodes, which was implemented in the package MorphoJ $1.06 \mathrm{c}$ (Klingenberg, 2011).

\section{a. Superimposition}

Centroid size (CS), the summed squared distances of each landmark from the centroid of the form, was used as a measure of size (Zelditch et al., 2012). Generalized Procrustes analysis was employed to obtain a matrix of shape coordinates from which all information related to position, scale and orientation were removed (Rohlf and Slice, 1990; Dryden and Mardia, 1998). The shape coordinates were analyzed in MorphoJ 1.06c (Klingenberg, 2011) to test whether there were specimens that largely deviated in shape from the other specimens. No outlier was identified in any of these datasets. These datasets were averaged by genus before further analyses. We used two methods to analyze the shape change of the upper edge along orbit. In the first method, all of the points were considered to be landmarks. In the second method, the original dataset was pre-aligned in tpsRelw version 1.54 (Rohlf, 2002) to allow for the sliding of semi-landmarks, which minimize the amount of shape change between each specimen and the Procrustes average of all the specimens.

b. Testing phylogenetic signal in shape and size Covariance matrices were generated for each dataset of genera means, which were then used in the principal component analyses (PCA). To test the phylogenetic signal of the morphological variation, we imported the Bayesian tree obtained from phylogenetic analyses and mapped the shape (Procrustes coordinates) and size (centroid size) data from genera means. The terminal branches of the phylogenetic tree were named by genus, and the shapes of the internal nodes of the phylogeny were reconstructed by squared-change parsimony (Maddison, 1991), which was weighted by genetic change on the respective branches of the tree. Through these calculations, the sum of squared changes of shape along the branches is minimized over the entire phylogeny reconstructed from the above analysis. We used a permutation approach (Klingenberg and Gidaszewski, 2010; Klingenberg and Marugan-Lobon, 2013), which simulated the null hypothesis of no phylogenetic signal in the data by randomly exchanging 
the shape data amongst the tips of the phylogenetic tree (Klingenberg and Gidaszewski, 2010; Klingenberg, 2011) in order to test the phylogenetic signal in the Procrustes coordinates. 10,000 random permutations were conducted and the total amount of squared change summed over all branches of the tree was the test statistic used. These analyses produced two output datasets: one with the values of the changes along the branches and the other with scores for phylogenetically independent contrasts, both of which are very important for analysing the evolutionary process of morphological data (Felsenstein, 1985; Klingenberg and MaruganLobon, 2013). Because the shape change of specific genera, is the focus of the present study, we used genera means in the analyses and not phylogenetic independent contrasts as units of analysis. To visualize the phylogenetic history of shape change at the generic level, the tree was mapped onto the PCA plots. We also reconstructed the centroid size of internal nodes of the tree by squared-change parsimony and then tested for the phylogenetic signal of size using a permutation approach. We also mapped centroid size of the different views of the skull onto the phylogeny.

c. Size correction of morphological data and evolutionary allometry

We used a multivariate regression of Procrustes coordinates (as shape variables) against $\log$ transformed centroid size (as size variables) to remove the effect of size on shape. We mapped the residuals from the above regression analyses onto the phylogenetic tree to test for phylogenetic signal of size-corrected shape variation. A large difference between the original dataset and the residuals would indicate that evolutionary allometry is an important factor in cranial evolution. To analyse how evolutionary change of shape is associated with evolutionary size change in different datasets, we regressed the independent contrast of shape (Procrustes coordinates) on the independent contrast of centroid size (Klingenberg and Marugan-Lobon, 2013). A significant result of this test would indicate evolutionary allometry.

\section{Results}

\section{Morphological comparison among extant lagomorph genera}

Representative figures for dorsal, ventral and lateral views of the cranium and the lateral view of the man- dible for these 12 extant genera are shown in Figs 3-5. The crania of Ochotona are significantly smaller than those of other lagomorph genera (ANOVA of log centroid size, $\mathrm{p}<0.001)$. Three ecotypes were recognized within Ochotona in previous studies, which included the northern group, the alpine group and the steppe group (Niu et al., 2004). The three specimens that represent each eco-group are given in Fig. 3. Among these species, O. koslowi (Fig. 3E-H) has the shortest interorbital distances, and the dorsal side of the cranium of this species protrudes the most, which can be identified from the lateral view. The cranium of $O$. thomasi (Fig. 3I-L) is the narrowest in width, but the maxillary fenestra is very wide. In all Ochotona species, the coronoid process is severely reduced.

Within Leporidae, Nesolagus, Pentalagus and Caprolagus have much heavier and thicker skulls than other genera (Figs 3M-P, 4Q-P, and 5A-D, respectively). They have well-developed posterior supraorbital processes, but no anterior supraorbital processes. The maxillary fenestra is almost closed in the latter two genera. The auditory bullae are prominently smaller in these three genera compared to that of other genera. Moreover, Caprolagus is quite different from other genera of leporids in a broader palatal bridge and a narrow incisive and palatal foramen (Fig. 5A-D). In Romerolagus, the surface of the posterior region of the frontal bone and the entire parietal bone is covered with small, concave dips (Fig. 4E-H). However, the skull of Romerolagus is smaller than the above three genera. The adult skull morphology of Brachylagus (Fig. 5M-P) is similar to that of a juvenile Lepus, which has the second smallest skull size amongst extant genera. The auditory bullae of Brachylagus are relatively larger compared to those of other genera. The supraorbital processes of lagomorphs are highly variable. For example, within Lepus, L. americanus and L. timidus display different shapes (Fig. 4I-P). Of all extant leporid genera, the palatine foramen, craniopharyngeal ducts and carotid canals are largest in Pentalagus. In contrast to other leporid genera, Nesolagus and Pentalagus have poorly developed coronoid processes and the broadest mandibular condyles and angles.

\section{Geometric morphometrics analysis at generic level}

No significant phylogenetic signal for variation in shape and size of analysed structures (dorsal, ventral and lateral views of cranium and mandible) was found. The phylogenetic tree (Fig. 6A) superimposed onto 


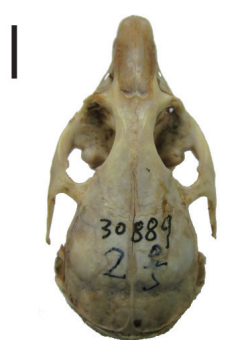

A

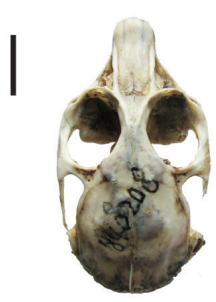

E
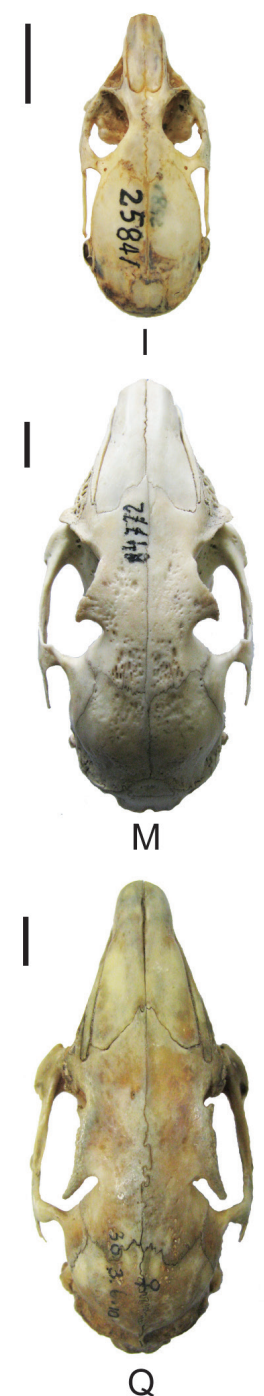

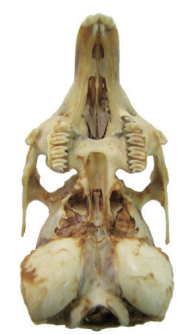

B

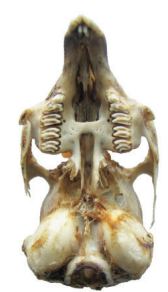

$\mathrm{F}$
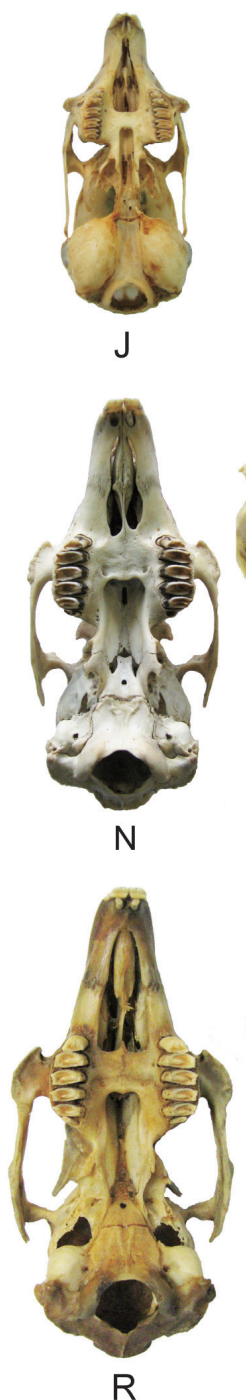

$\mathrm{R}$
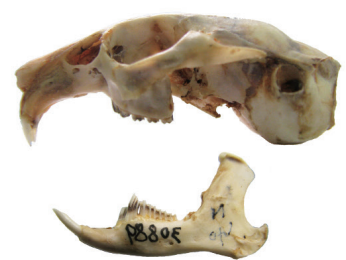

C

D
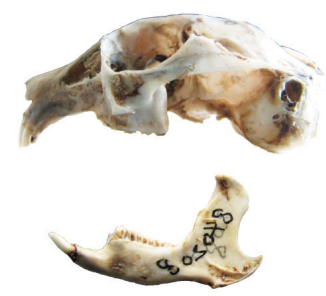

G

$\mathrm{H}$

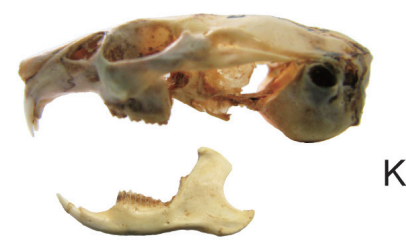

$\mathrm{L}$
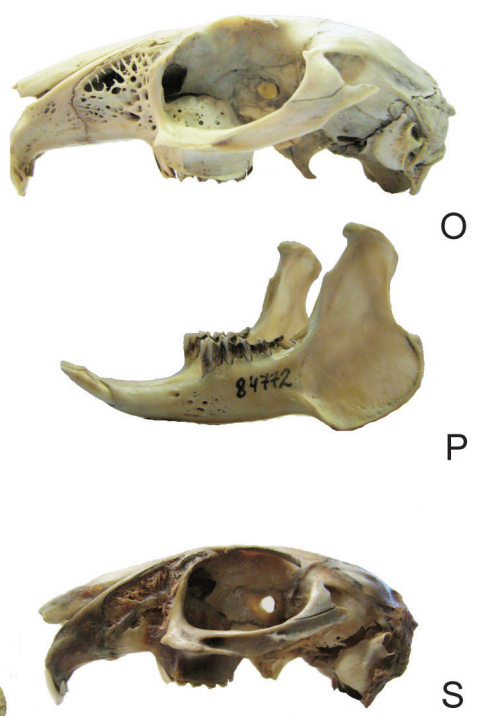

Fig. 3. Skulls of Ochotona, Nesolagus and Poelagus. A-D. O. argentata, specimen: IOZCAS 30889; E-H. O. koslowi, NIPBCAS 0006334; I-L. O. thomasi, IOZCAS 25841. M-P. Nesolagus timinsi, specimen: ZISPS: 84772; Q-T. Poelagus marjorita, specimen: BMNH 30.3.6.10. $\mathrm{A}, \mathrm{E}, \mathrm{I}, \mathrm{M}$, and $\mathrm{Q}$ are the dorsal views; $\mathrm{B}$, $\mathrm{E}, \mathrm{J}, \mathrm{N}$ and $\mathrm{R}$ are the ventral views; $\mathrm{C}, \mathrm{G}$, $\mathrm{K}, \mathrm{O}$ and $\mathrm{S}$ are the lateral views; $\mathrm{D}, \mathrm{H}, \mathrm{L}$, $\mathrm{P}$ and $\mathrm{T}$ are the lateral views of the mandible. Scale bar $=1 \mathrm{~cm}$. 


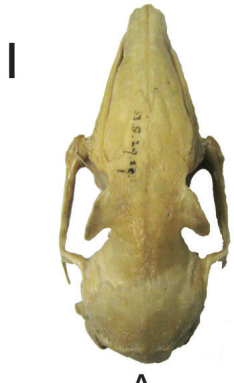

A

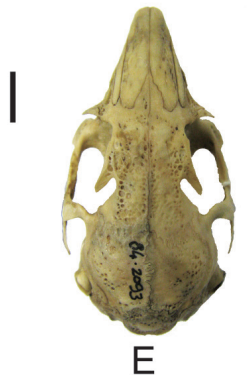

I

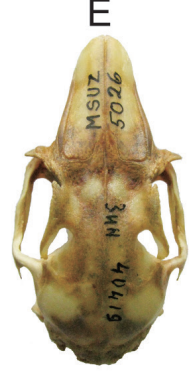

I

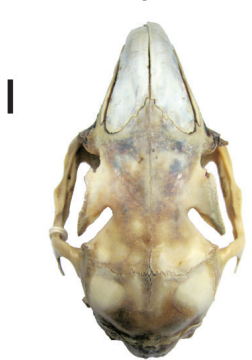

M

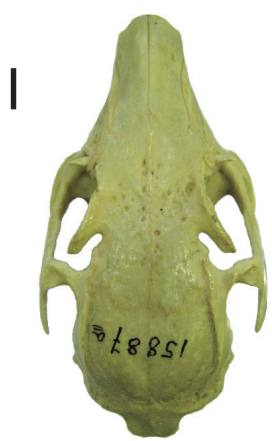

Q
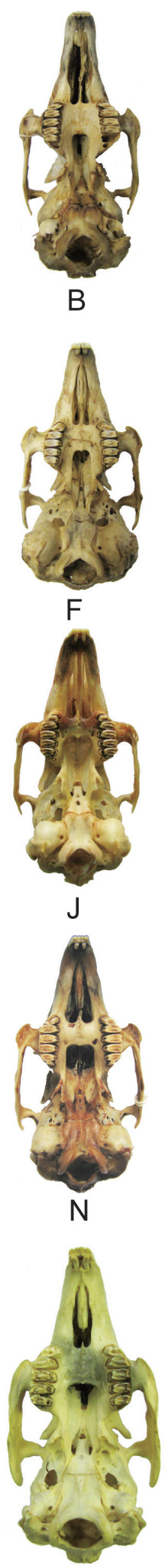

$\mathrm{R}$
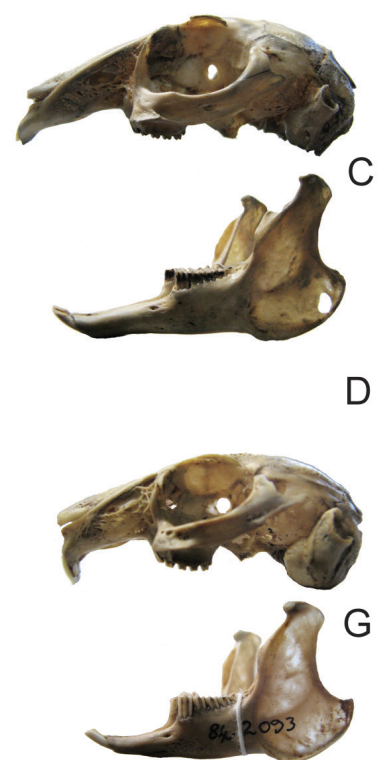

$\mathrm{H}$
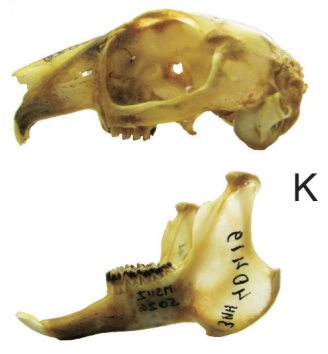

$\mathrm{L}$
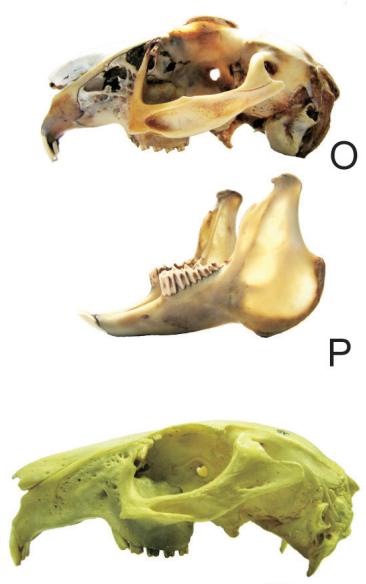

$\mathrm{S}$

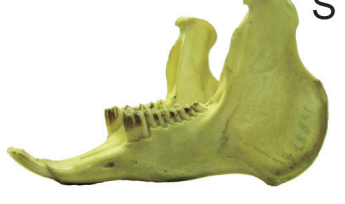

$\mathrm{T}$
Fig. 4. Skulls of Pronolagus, Romerolagus, Lepus and Pentalagus. A-D, Pronolagus crassicandatus, specimen: cranium, BMNH 53.8.29.29; mandible, BMNH 4.2.3.115. E-H, Romerolagus diazi, specimen: BMNH 842093; I-L, Lepus americanus, specimen: ZMMSU S-40419; M-P, L. timidus, specimen: IOZCAS 03013; Q-T, Pentalagus furnessi, specimen: ZISP S-15887. A, E, I, $\mathrm{M}, \mathrm{Q}$ are the dorsal views; $\mathrm{B}, \mathrm{E}, \mathrm{J}, \mathrm{N}$ and $R$ are the ventral views; $C, G, K, O$ and $S$ are the lateral views; $\mathrm{D}, \mathrm{H}, \mathrm{L}, \mathrm{P}$ and $\mathrm{T}$ are the lateral views of the mandible. Scale bar $=1 \mathrm{~cm}$. 


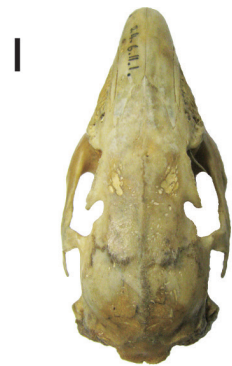

A

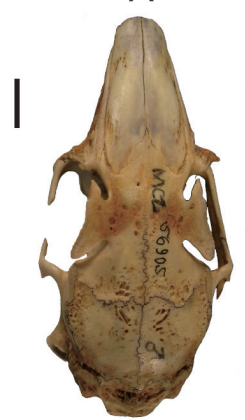

E
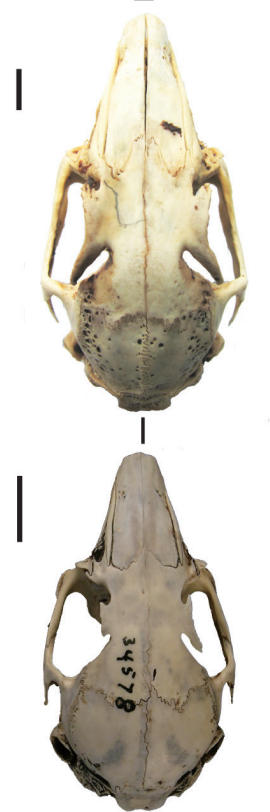

M

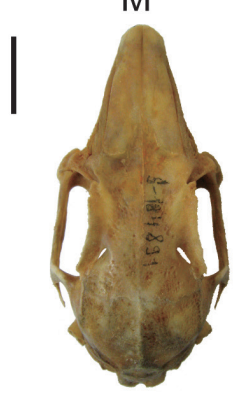

Q

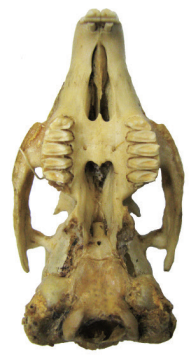

B

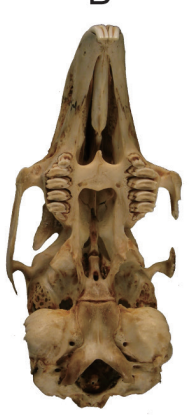

$\mathrm{F}$
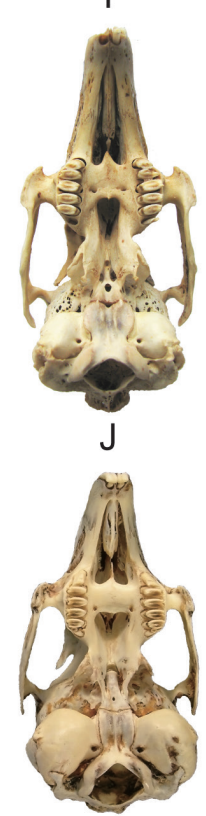

$\mathrm{N}$

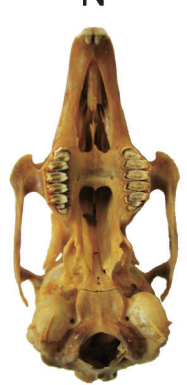

$\mathrm{R}$
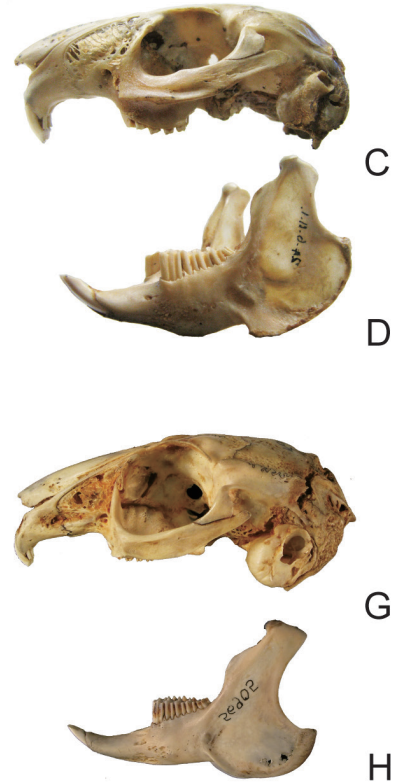

G

$\mathrm{H}$
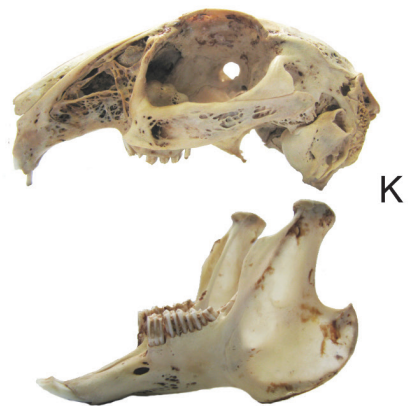

L
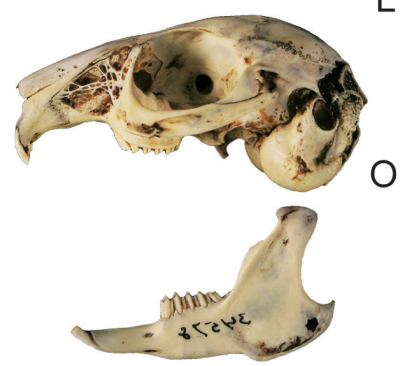

$\mathrm{P}$
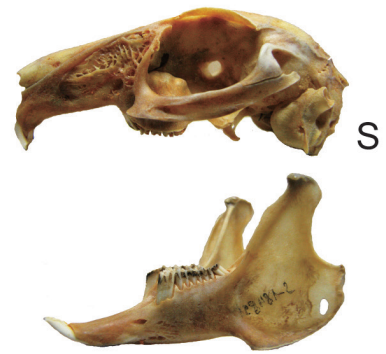

$\mathrm{T}$
Fig. 5. Skulls of Caprolagus, Bunolagus, Oryctolagus, Brachylagus and Sylvilagus. A-D, Caprolagus hispidus, specimen: BMNH 24.6.11.1; E-H, Bunolagus monticularis, specimen: MCZ 56905. I-L, Oryctolagus cuniculus, specimen: IOZCAS, No collection number available; M-P, Brachylagus idahoensis, specimen: MCZ 34578; Q-T, Sylvilagus floridanus, specimen: ZMMSU 184891. A, $\mathrm{E}, \mathrm{I}, \mathrm{M}$ and $\mathrm{Q}$ are the dorsal views; B, E, $\mathrm{J}, \mathrm{N}$ and $\mathrm{R}$ are the ventral views; $\mathrm{C}, \mathrm{G}, \mathrm{K}$, $\mathrm{O}$ and $\mathrm{S}$ are the lateral views; $\mathrm{D}, \mathrm{H}, \mathrm{L}, \mathrm{P}$ and $\mathrm{T}$ are the lateral views of the mandible. Scale bar $=1 \mathrm{~cm}$. 

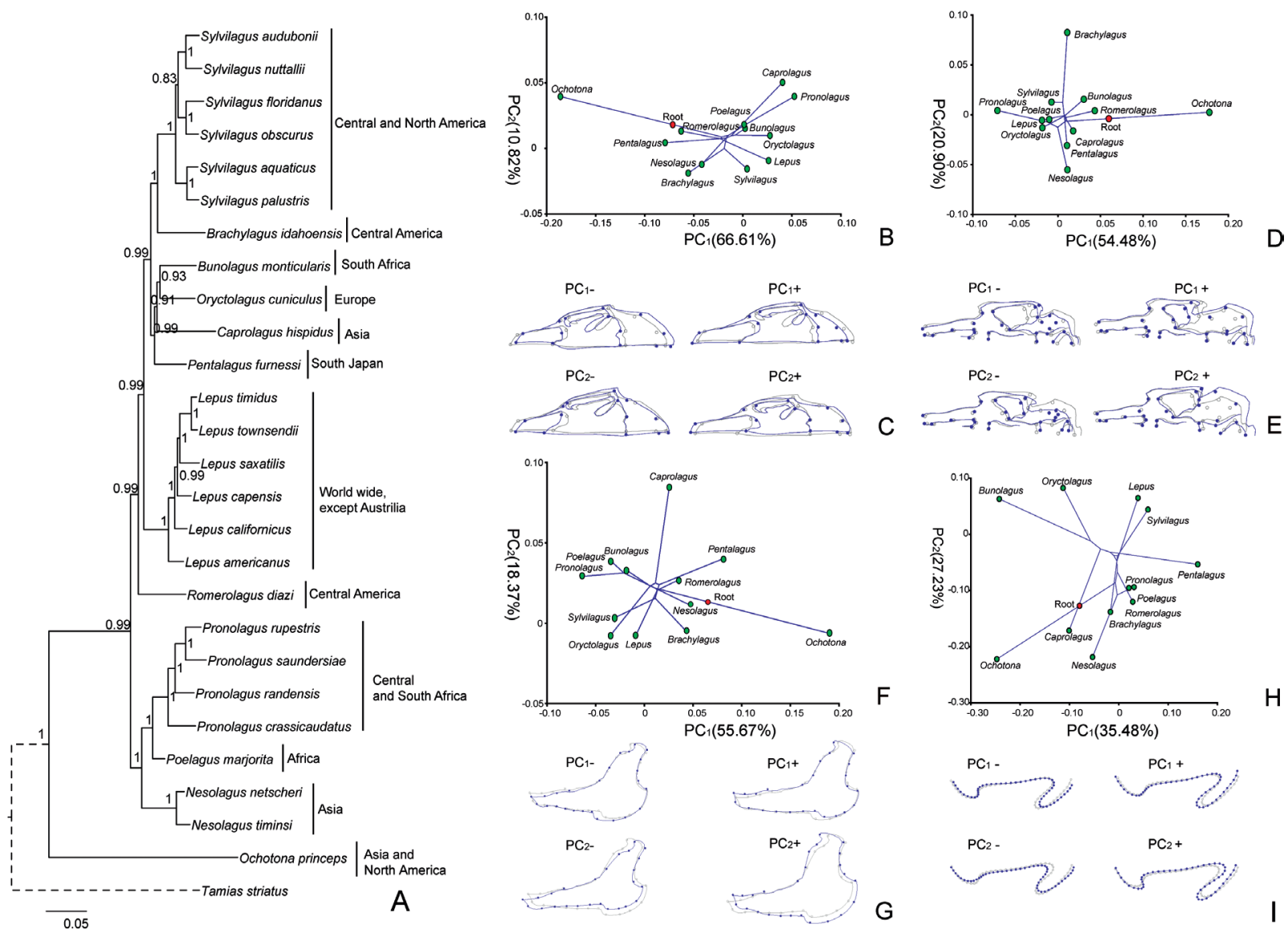

G

Fig. 6. Mapping phylogenetic tree onto shape change of the skull. The phylogeny was mapped onto PCA plots by reconstructing shapes at the internal nodes by squared-change parsimony, and PCs are used to display as much of the variation as possible in a few dimensions. All genera included in the analysis are labeled. A. Phylogenetic tree of extant Lagomorpha reconstructed from seven DNA fragments (Matthee et al., 2004). B-I. Shape change of Lagomorpha crania inferred from geometric morphometric analyses. B, D, F, H. Mapping the shape change of the dorsal cranium, ventral cranium, mandible and the upper edge along the orbit, respectively, onto the phylogeny of extant Lagomorpha genera. The percent of total shape change explained by $\mathrm{PC}_{1}$ and $\mathrm{PC}_{2}$ are given in the parentheses. The four diagrams next to each PCA plot (C, G, E and I) indicate the skull shapes for a score of -0.1 or +0.1 for the respective PC. The warping of outline diagrams is based on a thin-plate spline for the landmarks. The warping outline drawings and landmarks in grey give the shape information for the consensus shape (starting shape), and the blue colored warping of the outline drawings and landmarks give the shape information of the target shape.

scatter plots of shape space defined by the first two principal components is shown in Fig. 6 (B, D, F and $\mathrm{H})$. The projection of the phylogenetic tree onto the PC plots showed extensive branch crossing and long branches closely related genera (Fig. 6B, D, F and H). Ochotona is largely different from all leporid genera. PCA results of original datasets and the size corrected dataset are moderately different (Table 1). Significant evolutionary allometry was identified in the dorsal and ventral views of the cranium and the lateral view of the mandible. Size variation explains $26.95 \%, 26.78 \%$, and $28.94 \%$ of total morphological variation in the ventral and dorsal views of the cranium, and the mandible respectively, while it explains $10.89 \%$ of total morphological variation in the UEAO. Size variation amongst genera is similar in different datasets. Here, we give the plots of the dorsal view as an example to show size change along the tree. In Fig. 7A, the vertical direction corresponds to the cumulative branch length from the root of the tree, and Fig. 7B indicates a statistically 


\begin{tabular}{|c|c|c|c|c|}
\hline \multirow[t]{2}{*}{$\mathrm{PC}_{\mathrm{s}}$} & \multicolumn{2}{|l|}{ Uncorrected } & \multicolumn{2}{|l|}{ Size corrected } \\
\hline & Eigenvalues & $\%$ total variance & Eigenvalues & $\%$ total variance \\
\hline \multicolumn{5}{|c|}{ Dorsal view } \\
\hline $\mathrm{PC}_{1}$ & 0.00454 & 66.61 & 0.00311 & 62.62 \\
\hline $\mathrm{PC}_{2}$ & 0.00074 & 10.82 & 0.00074 & 14.81 \\
\hline $\mathrm{PC}_{3}^{2}$ & 0.00060 & 8.82 & 0.00034 & 6.88 \\
\hline $\mathrm{PC}_{4}$ & 0.00025 & 3.67 & 0.00025 & 5.02 \\
\hline $\mathrm{PC}_{5}$ & 0.00018 & 2.63 & 0.00017 & 3.55 \\
\hline \multicolumn{5}{|c|}{ Ventral view } \\
\hline $\mathrm{PC}_{1}$ & 0.00352 & 54.48 & 0.00259 & 54.67 \\
\hline $\mathrm{PC}_{2}$ & 0.00135 & 20.90 & 0.00078 & 16.48 \\
\hline $\mathrm{PC}_{3}^{2}$ & 0.00053 & 8.20 & 0.00052 & 10.96 \\
\hline $\mathrm{PC}_{4}^{3}$ & 0.00034 & 5.32 & 0.00030 & 6.23 \\
\hline $\mathrm{PC}_{5}^{4}$ & 0.00027 & 4.17 & 0.00019 & 3.93 \\
\hline
\end{tabular}

Mandible

\begin{tabular}{lrrrr}
\hline $\mathrm{PC}_{1}$ & 0.00498 & 55.67 & 0.00322 & 50.64 \\
$\mathrm{PC}_{2}$ & 0.00164 & 18.37 & 0.00109 & 17.11 \\
$\mathrm{PC}_{3}$ & 0.00106 & 11.82 & 0.00971 & 15.27 \\
$\mathrm{PC}_{4}$ & 0.00044 & 4.90 & 0.00037 & 5.78 \\
$\mathrm{PC}_{5}$ & 0.00033 & 3.71 & 0.00030 & 4.78 \\
\hline
\end{tabular}

Upper edge along orbit

\begin{tabular}{lrrrr}
\hline $\mathrm{PC}_{1}$ & 0.01677 & 35.48 & 0.01567 & 36.70 \\
$\mathrm{PC}_{2}$ & 0.01287 & 27.23 & 0.01142 & 26.76 \\
$\mathrm{PC}_{3}$ & 0.00842 & 17.83 & 0.00833 & 19.51 \\
$\mathrm{PC}_{4}$ & 0.00566 & 11.98 & 0.00408 & 9.57 \\
$\mathrm{PC}_{5}$ & 0.00190 & 4.03 & 0.00181 & 4.24 \\
\hline
\end{tabular}

Table 1. PCA of variation among the shapes of genus means, both for the original and size-corrected shape data
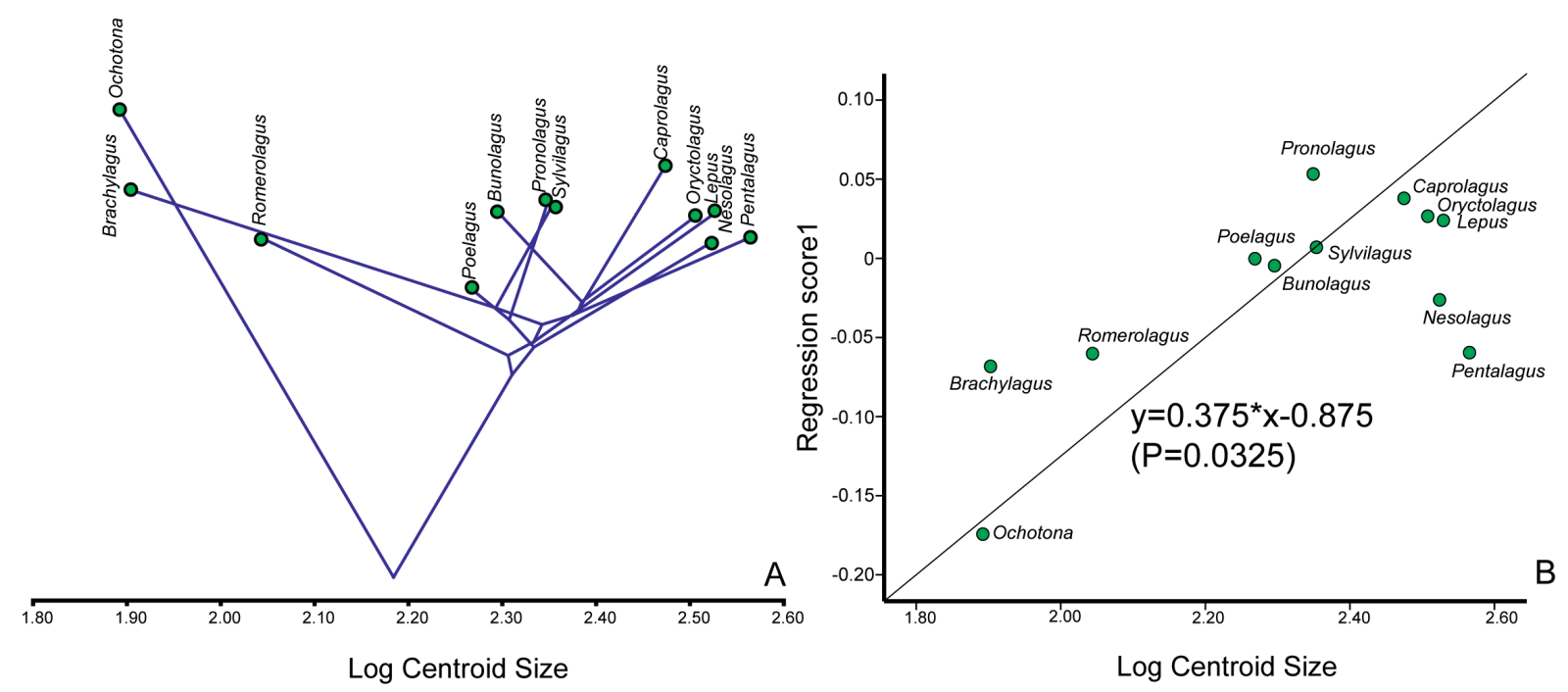

Fig. 7. Mapping phylogenetic tree onto size change of the skull. A. Mapping log transformed centroid size change of the dorsal cranium onto the phylogeny of extant genera in Lagomorpha. B. Regression of Procrustes coordinates onto log transformed centroid size. 
significant positive relationship between size and shape $(\mathrm{P}=0.0325)$.

\section{a. Dorsal view}

The PCA of the dorsal view shows that the first five PCs captured $66.61 \%, 10.82 \%, 8.81 \%, 3.67 \%$ and $2.63 \%$ of total shape variation, respectively. The 12 genera we analysed form a loose distribution (Fig. 6, B and $\mathrm{C}$ ). Shape changes associated with $\mathrm{PC}_{1}$ is mainly due to the change in relative length of the cranium, particularly the proportion of pre-orbital, inter-orbital and post-orbital regions. Shape change correlated with $\mathrm{PC}_{2}$ is mainly in relation to the relative width of postorbital regions. Mapping cranial shape of the dorsal view onto the phylogeny using squared-change parsimony resulted in a tree length of 0.05 , which was measured in units of squared Procrustes distance along all branches. The permutation test for a phylogenetic signal in the shape data is statistically insignificant $(\mathrm{P}=0.13)$. Size-corrected shape data resulted in a tree length of 0.042 , with $\mathrm{P}=0.28$. Similarly, mapping centroid size onto the phylogeny resulted in a tree length of 44.95, which was measured in units of squared centroid size distance along all branches (Fig. $7 \mathrm{~A})$, with a statistically insignificant permutation test $(\mathrm{P}=0.33)$. Regressing the independent contrast of shape onto the independent contrast of log centroid size in the dorsal view of the cranium accounts for $13.24 \%$ of the variation in shape, and there is a statistically insignificant trend $(\mathrm{P}=0.22)$.

\section{b. Ventral view}

The PCA of the ventral view shows that the first five PCs accounted for $54.48 \%, 20.90 \%, 8.20 \%, 5.32 \%$ and $4.17 \%$ of total shape variation, respectively. The 12 genera again formed a loose scatter (Fig. 6D and E). Shape changes associated with $\mathrm{PC}_{1}$ are mainly in relation to the relative length of the nostrum and the size of the orbit, which are indicated by the warping of the outline drawings. Shape change associated with $\mathrm{PC}_{2}$ is primarily due to the relative width of the post-orbital region and the size of the foramen magnum. Mapping the cranial shape of the ventral view onto the phylogeny resulted in a tree length of 0.05 . The permutation test for a phylogenetic signal in the shape data is statistically insignificant $(\mathrm{P}=0.06)$. Size-corrected shape data resulted in a tree length of 0.04 with $\mathrm{P}=0.12$. Mapping the centroid size of the ventral view onto the phylogeny resulted in a tree length of 80.00 with a statistically insignificant permutation test $(\mathrm{P}=0.47)$. Regressing the independent contrast of shape onto the independent contrast of log centroid size in the ventral view of the cranium captured $19.65 \%$ of the variation in shape, and there is a slight trend between the variables $(\mathrm{P}=0.052)$.

\section{c. Mandible}

The PCA of the lateral view of the mandible shows that the first five PCs captured 55.67\%, 18.37\%, $11.82 \%, 4.90 \%$ and $3.71 \%$ of total shape variation, respectively. A loose scatter of taxa was formed from the 12 genera (Fig. 6F and G). Shape changes associated with $\mathrm{PC}_{1}$ and $\mathrm{PC}_{2}$ are mainly due to the relative length of the anterior and posterior alveolar ridges and the expansion of the mandibular angle vertical to the tooth row. Mapping the mandible shape onto the phylogeny obtained a tree length of 0.07 . The permutation test for a phylogenetic signal in the shape data is statistically insignificant $(\mathrm{P}=0.19)$. Size-corrected shape data resulted in a tree length of 0.06 with $\mathrm{P}=0.62$. Mapping centroid size of the mandible onto the phylogeny obtained a tree length of 29.16 with a statistically insignificant permutation test $(\mathrm{P}=0.08)$. Regressing the independent contrast of shape onto the independent contrast of log centroid size in the lateral view of the mandible explained $9.89 \%$ of the variation in shape, and there is a statistically insignificant correlation between the two variables $(\mathrm{P}=0.38)$.

\section{d. Upper edge along orbit}

When we consider all of the points sampled on the curve as landmarks, the PCA shows that $\mathrm{PC}_{1}$ to $\mathrm{PC}_{5}$ captured $35.48 \%, 27.23 \%, 17.83 \%, 11.98 \%$ and $4.03 \%$ of total shape variation, respectively. The 12 genera formed a loose scatter (Fig. $6 \mathrm{H}$ and I). Mapping the orbit line shape onto the phylogeny using squaredchange parsimony obtained a tree length of 0.28 . The permutation test for a phylogenetic signal in the shape data is statistically insignificant $(\mathrm{P}=0.27)$. Size-corrected shape data resulted in a tree length of 0.35 with $\mathrm{P}=0.16$. Mapping centroid size of UEAO onto the phylogeny obtained a tree length of 14.86 with a statistically insignificant permutation test $(\mathrm{P}=0.44)$. Interestingly, regressing the independent contrast of shape onto the independent contrast of log centroid size in UEAO accounts for $58.96 \%$ of the shape variation, and there is a statistically insignificant correlation between the two variables $(\mathrm{P}=0.39)$. Similarly, when we pre-aligned the dataset by considering 48 points between the start point and end point as semilandmarks, the PCA shows that $\mathrm{PC}_{1}$ to $\mathrm{PC}_{5}$ captured $44.58 \%, 21.15 \%, 17.48 \%$, $6.87 \%$ and $3.88 \%$ of total shape variation, respectively. 
Mapping the shape onto the phylogeny obtained a tree length of 0.28 with a statistically insignificant phylogenetic signal $(\mathrm{P}=0.27)$.

\section{Discussion}

\section{Phylogenetic signals at the generic level}

Phenotypic data (including size and shape) and DNA markers often tell different stories about organismal evolution, with molecular data generally regarded as more accurate than morphology (Cardini and Elton, 2008). The vast phenotypic diversity of organisms on earth is a combined result of developmental constraint determined by genetic inheritability and ecological adaptation guided by environmental changes, although the influence of these endogenous and exogenous factors varies in different organisms. For example, significant phylogenetic signals were identified in the wing shape of Culicoides (Diptera: Ceratopogonidae) (Munoz-Munoz et al., 2011), the wing shape of a Drosophila melanogaster subgroup (Klingenberg and Gidaszewski, 2010), or in the skull and body shape morphology of triturus newts (Ivanovic and Arntzen, 2014). However, morphological traits and DNA sequences evolve at independent rates, which could result in their decoupling. Environmentally plastic responses and parallel functional adaptations appeared as the two major reasons for the absence of phylogenetic signal. Caumul and Polly (2005) pointed out that a good phylogenetic signal in quantitative skeletal morphology is likely to be found only when the taxa have a common ancestry no older than millions of years (1\% to $10 \%$ mtDNA divergence). This point of view suggests that the process of evolutionary history also influenced the maintenance of phylogenetic signals in morphological evolution.

Our analyses did not find a statistically significant phylogenetic signal in the skull shape variation of lagomorphs at the generic level. Even the ventral cranium, which was considered the best morphological feature for recovering phylogenetic relationships (Caumul and Polly, 2005), showed statistically insignificant phylogenetic signal in lagomorphs at the generic level. These results demonstrate that lagomorph skull morphology is probably more susceptible to exogenous factors, which drive convergent evolution. The evolutionary history of lagomorphs, including fossils, was traced in our previous studies, which identified different evolutionary dynamics for ochotonids and leporids due to their responses to historical global vegetation change (Ge et al., 2013). The diversification of ochotonids and leporids could be traced back to 52 million years ago (Rose et al., 2008), and the divergence of extant leporids was around the late Miocene. Besides homoplasy, another major reason for the difficulties of establishing a higher-level phylogeny of lagomorphs and the absence of phylogenetic signal at the generic level is probably because of a relatively long evolutionary history of Lagomorpha, and the extinction of numerous lineages. According to our previous studies, about 34 genera of ochotonids and 45 genera of leporids had been present throughout evolution, but only one relic genus of ochotonids and 11 genera of leporids currently survive in different habitats, although several of them are now threatened due to habitat destruction $(\mathrm{Ge}$ et al., 2013). In the absence of several taxa, phylogenetic signals of skull shape were most likely diluted. Reconstructing an intergeneric phylogeny based on morphological data was also likely influenced by the loss of these signals.

\section{Morphological adaptation in the skull of lagomorphs}

Geometric morphometric analyses identified the loss of phylogenetic signals in skull shape change at the generic level in Lagomorpha. The higher-level skull shape evolution of these taxa was likely guided by ecological adaptation. The skull shape change of lagomorphs at the generic level is dominated by increasing facial size and auditory bullae size in open habitats. A shorter nasal bone is presented in primitive taxa, such as Ochotona and Romerlagus. The facial length is believed to bear great evolutionary flexibility in mammals (Cardini and Polly, 2013). Facial bones are largely elongated in lagomorphs that diverged later, particularly in Leporidae. A smaller auditory bullae is most likely adapted for a forest environment, where predation pressure is lower when compared with open grasslands. For example, Pentalagus (Fig. 4Q-T) inhabits the forests of Japan's surrounding islands while Nesolagus (Fig. 3MP), and Caprolagus (Fig. 5A-D) live in the forests of Southeast Asia. Possessing large auditory bullae are adapted to more open habitats (Green and Flinders 1980), as exemplified by the habitats of Brachylagus (Fig. 5M-P) and Lepus (Fig. 4I-P). Brachylagus has large auditory bullae and is endemic to central North America where there is relatively short sagebrush, and Lepus has large auditory bullae and resides in open habitats such as the Taklimakan Desert in China where L. yarkandensis is endemic. This is also evidenced by 
the greatly inflated auditory bullae in jerboas and kangaroo rats (Vial, 1962) that occupy arid regions. This adaptation is of value in detecting potential predators and maintaining balance during jumping and running (Feldhamer et al., 1999).

The mammalian orbit is a highly plastic region of the skull (Cox, 2008). Presence of a supraorbital process or a well-developed postorbital bar have evolved in mammals multiple times (Heesy, 2005). Different hypotheses were proposed to explain the function of this region (Prince 1953; Simons, 1962; Cartmill, 1970; Greaves, 1985). According to the shape distance of the supraorbital processes in lagomorphs, Nesolagus is more closely related to Caprolagus, Lepus is more closely related to Sylvilagus, and Oryctolagus, Romerolagus, Pronolagus and Poelagus are more closely related to each other (Fig. $6 \mathrm{H}$ ). However, this result is distinct from the molecular phylogeny reconstructed from the combined matrix of seven DNA sequences (Matthee et al., 2004). Both the anterior and posterior supraorbital processes are absent in Ochoto$n a$, but well developed in Leporidae genera, and they are most prominent in species that inhabit grasslands, plateaus or deserts. These structures probably function to protect eyes and lacrimal glands during high speed running. Additionally, vascularization of the oral cavity was enhanced. This adaptation can be interpreted in terms of improved means of thermoregulation in species living in warmer and more arid conditions than their forest-dwelling ancestors (Lopez-Martinez, 2001). It allows them to increase blood flow through the mucous membranes in the oral cavity and more effectively cool themselves by panting as a result (Fostowicz-Frelik and Meng, 2013). Shape variation of the supraorbital processes is observed in individuals of various ages, as well as in populations of Lepus that inhabit different habitats (Lu, 2003; Averianov et al., 1994). In fact, supraorbital processes are also present in Sciuridae, a group of animals within Rodentia, which indicates the multiple times of origination within glires (Cardini et al., 2005, Cardini and O'Higgins, 2005). The supraorbital processes are useful as diagnostic characters in taxonomy, but from our results, we caution against using the characteristics of this structure in phylogenetic reconstructions.

Unlike shape and size changes at the generic level, a significant phylogenetic association was found in the body length evolution of lagomorphs by a Mantel test, which calculated the correlation of phylogenetic distance and body length difference at the species level (Ge et al., 2013). Craniometric data of Oryctolagus cuniculus indicated that skull size was positively correlated with latitude and negatively correlated with ambient temperature (Sharples et al., 1996). Besides latitude, analyses based on linear measurements revealed that the northern hare populations had a more rapid rate of cranial growth when compared to the southern populations (Lu et al., 2003). In lagomorphs, genera with small body sizes, such as Ochotona and Brachylagus, depend highly on $\mathrm{C}_{3}$ plants, while those that have evolved larger body sizes are capable of choosing $\mathrm{C}_{4}$ plants in their diet (Ge et al., 2013). This phenomenon was also observed in other herbivorous mammals (Mihlbachler et al., 2011), for which diet change may play an important role in their morphological evolution.

Paleontological studies revealed that lagomorphs are notable for their conservative morphological evolution for over 50 million years (Fostowicz-Frelik and Meng, 2013). Phylogenetic constraints, forage preferences, and habitat differences likely affect the shape and size evolution of these animals. However, extensive extinction not only wiped out biodiversity but also decreased the continual succession of morphological evolution, thus providing fragmented phylogenetic information in the surviving genera. For a more comprehensive scenario of the phylogeny and evolutionary processes within Lagomorpha, extensive cooperation between palaeontologists and researchers who study extant taxa is necessary.

\section{Acknowledgements}

We appreciate Drs. Averianov Alexander, Voita Leonid, Alexei V. Abramov, Barahova Galina, Golenishcher Fedor and Malikov Vlad from the Zoological Museum of the Zoological Institute of the Russian Academy of Sciences, Drs. Andrey A. Lissovsky, Sergei Kruskop and Mr. Vladimir S. Lebedev from the Zoological Museum of the Moscow State University, and Mr. Wenjin Li, Xiaochen Cheng from the Northwest Institute of Plateau Biology Chinese Academy of Sciences, and Xiaoping Chao from the Institute of Zoology Chinese Academy of Sciences, for their assistance with the specimens preserved in their institute. We thank Judy Chupasko of the Comparative Zoological Museum of Harvard University for helping us take photos of the specimens at MCZ. We thank William Stanley at the Field Museum of Natural History and Roberto Portela Miguez at the Natural History Museum in London for allowing us access to the specimens. We thank Professors Rohlf F. James, Jin Meng, Andrew T. Smith and Christian P. Klingenberg for their constructive suggestions in improving this manuscript. We appreciate editors and anonymous reviewers for the constructive suggestions. Our research is sponsored by grants from the Natural Science Foundation of China (No: 31101629, 
31272289, 31172065, J1210002) and a grant (Y229YX5105) from the Key Laboratory of Zoological Systematics and Evolution of the Chinese Academy of Sciences.

\section{References}

Asher RJ, Meng J, Wible JR, McKenna MC, Rougier GW, Dashzeveg D, Novacek MJ. 2005. Stem Lagomorpha and the antiquity of Glires. Science 307: 1091-1094.

Averianov AO, Abramov AV, Tikhonov AN. 2000. A new species of Nesolagus (Lagomorpha, Leporidae) from Vietnam with osteological description. Contributions from the Zoological Institute St Petersburg 3: 1-22.

Averianov AO. 1994. Morphotypic variation of the skull and teeth in east-Asian species of the genus Lepus (Lagomorpha, Leporidae). Zoologicheskii Zhurnal 73: 132-139.

Bensley BA. 1948. Pratical anatomy of rabbit. 8th edition. University of Toronto Press.

Bramble DM, Carrier DR. 1983. Running and breathing in mammals. Science 219: 251-256.

Bramble DM. 1989. Cranial specialization and locomotor habit in the Lagomorpha. American Zoologist 29: 303-317.

Cardini A, Elton S. 2008. Does the skull carry a phylogenetic signal? Evolution and modularity in the guenons. Biological Journal of the Linnean Society 93: 813-834.

Cardini A, Hoffmann RS, Thorington RW. 2005. Morphological evolution in marmots (Rodentia, Sciuridae): size and shape of the dorsal and lateral surfaces of the cranium. Journal of Zoological Systematics and Evolutionary Research 43: 258-268.

Cardini A, O’Higgins P. 2005. Post-natal ontogeny of the mandible and ventral cranium in Marmota species (Rodentia, Sciuridae): allometry and phylogeny Zoomorphology 124: 189-203.

Cardini A, Polly PD. 2013. Larger mammals have longer faces because of size-related constraints on skull form. Nature Communication 4: 2458.

Cartmill M. 1970. The orbits of arboreal mammals: a reassessment of the arboreal theory of primate evolution. Ph.D. dissertation. Chicago, IL: University of Chicago.

Caumul R, Polly PD. 2005. Phylogenetic and environmental components of morphological variation: skull, mandible, and molar shape in Marmots (Marmota,Rodentia). Evolution 59: 2460-2472.

Corbet GB. 1983. A review of classification in the family Leporidae. Acta Zoologica Fennica 174: 11-15.

Cox PG. 2008. A quantitative analysis of the Eutherian orbit: correlations with masticatory apparatus. Biological review 83: 35-69.

Dawson MR. 1969. Osteology of Prolagus sardus, a Quaternary ochotonid (Mammalia, Lagomorpha). Palaeovertebrata 4: 157-190.

Dawson MR. 1981. Evolution of modern leporids. Pp. 1-8 in: Myers K, MacInnes CD, eds, Proceedings of the World Lagomorph Conference. University of Guelph Press, Ontario.

Dryden IL, Mardia KV. 1998. Statistical Shape Analysis. Chichester: Wiley.

Feldhamer GA, Drickamer LC, Vessey SH, Merritt JF. 1999. Mammalogy: adaptation, diversity and ecology. Boston, Burr Ridge etc: WCB/McGraw-Hill.
Felsenstein J. 1985. Phylogenies and the Comparative Method. American Naturalist 125: 1-15.

Fostowicz-Frelik Ł, Meng J. 2013. Comparative morphology of premolar foramen in lagomorphs (Mammalia: Glires) and its functional and phylogenetic implications. PLOS ONE 8: e79794.

Ge DY, Wen ZX, Xia L, Zhang ZQ, Erbajeva M, Huang CM, Yang QS. 2013.Evolutionary history of lagomorphs in response to global environmental change. PLOS ONE 8: e59668.

Greaves WS. 1985. The mammalian postorbital bar as a torsionresisting helical strut. Journal of Zoology 207:125-136.

Green JS, Flinders JT. 1980. Brachylagus idahoensis. Mammalian Species 125: 1-4.

Heesy CP. 2005. Function of the mammalian postorbital bar. Journal of Morphology 264: 363-380.

Hoffmann RS, Smith AT. 2005. Order Lagomorpha. Pp. 185211 in: Wilson DE, Reeder DM, eds, In mammal species of the world: a taxonomic and geographic reference. Johns Hopkins University Press, London.

Ivanovic A, Arntzen JW. 2014. Evolution of skull and body shape in triturus newts reconstructed from three-dimensional morphometric data and phylogeny. Biological Journal of the Linnean Society, 113: 243-255.

Klingenberg CP, Gidaszewski NA. 2010. Testing and quantifying phylogenetic signals and homoplasy in morphometric data. Systematic Biology 59: 245-261.

Klingenberg CP, Marugan-Lobon J. 2013. Evolutionary covariation in geometric morphometric data: analyzing integration, modularity and allometry in a phylogenetic context. Systematic Biology 62: 591-610.

Klingenberg CP. 2011. MorphoJ: an integrated software package for geometric morphometrics. Molecular Ecology Resources $11: 353-357$.

Koenigswald W, Anders U, Engels S, Schultz JA, Ruf I. 2010. Tooth morphology in fossil and extant Lagomorpha (Mammalia) reflects different mastication patterns. Journal of Mammalian Evolution 17: 275-299.

Li CK, Meng J, Wang YQ. 2007. Dawsonolagus antiquus, a primitive lagomorph from the Eocene Arshanto Formation, Nei Mongol, China. Bulletin of Carnegie Museum of Natural History 39: 97-110.

Liu J, Yu L, Arnold ML, Wu CH, Wu SF, Lu X, Zhang YP. 2011. Reticulate evolution: frequent introgressive hybridization among Chinese hares (genus Lepus) revealed by analyses of multiple mitochondrial and nuclear DNA loci. BMC Evolutionary Biology 11: 223.

Lopez-Martinez N. 2001. Paleobiogeographical history of Prolagus, an European ochotonid (Lagomorpha). Lynx 32: 215231.

Lu X. 2003. Postnatal growth of skull linear measurements of Cape hare Lepus capensis in northern China: An analysis in an adaptive context. Biological Journal of the Linnean Society 78: 343-353.

Luo ZX. 1986. The Chinese hare. China Forestry Publishing House, Beijing.

Maddison WP. 1991. Squared-Change parsimony reconstructions of ancestral states for continuous-valued characters on a phylogenetic tree. Systematic Zoology 40: 304-314.

Matthee C, Van Vuuren B, Bell D, Robinson T. 2004. A molecular supermatrix of the rabbits and hares (Leporidae) al- 
lows for the identification of five intercontinental exchanges during the Miocene. Systematic Biology 53: 433-447.

Mihlbachler MC, Rivals F, Solounias N, Semprebon GM. 2011. Dietary change and evolution of horses in North America. Science 331: 1178-1181.

Munoz-Munoz F, Talavera S, Pages N. 2011. Geometric morphometrics of the wing in the subgenus Culicoides (Diptera: Ceratopogonidae): from practical implications to evolutionary interpretations. Journal of Medical Entomology 48: 129-139.

Niu Y, Wei FW, Li M, Liu XM, Feng ZJ. 2004. Phylogeny of pikas (Lagomorpha, Ochotona) inferred from mitochondrial cytochrome b sequences. Folia Zoologica 53: 141-155.

Posada D. 2008. jModelTest: phylogenetic model averaging. Molecular Biology and Evolution 25: 1253-1256.

Prince JH. 1953. Comparative anatomy of the orbit. British Journal of Physiological Optics 10: 144-154.

Robinson T, Matthee C. 2005. Phylogeny and evolutionary origins of the Leporidae: A review of cytogenetics, molecular analyses and a supermatrix analysis. Mammal Review 35: 231-247.

Rohlf FJ, Slice D. 1990. Extensions of the procrustes method for the optimal superimposition of landmarks. Systematic Zoology 39: 40-59.

Rohlf FJ. 2002. TPS series. Department of Ecology and Evolution, State University of Newyork, Stony Brook, New York. http://life.bio.sunysb.edu/morph/.

Ronquist F, Huelsenbeck JP. 2003. MrBayes 3: Bayesian phylogenetic inference under mixed models. Bioinformatics 19: 1572-1574.

Rose KD, DeLeon VB, Missiaen P, Rana RS, Sahni A, Singh L, Smith T, 2008. Early Eocene lagomorph (Mammalia) from Western India and the early diversification of Lagomorpha. Proceedings of the Royal Society of London Series B-Biological Sciences 275: 1203-1208.

Sharples CM, Fa JE, Bell DJ. 1996. Geographical variation in size in the European rabbit Oryctolagus cuniculus (Lagomorpha: Leporidae) in western Europe and North Africa. Zoological Journal of the Linnean Society 117: 141-158.

Simons EL. 1962. Fossil evidence relating to the early evolution of primate behavior. Annals of the New York Academy of Sciences 102: 282-294.
Yang AF. 1979. Anatomy of rabbit. Science press, Beijing.

Smith AT, Weston ML. 1990. Ochotona princeps. Mammalian Species 252: 1-8.

Stoner CJ, Bininda-Emonds ORP, Caro T. 2003. The adaptive significance of coloration in lagomorphs. Biological Journal of the Linnean Society 79: 309-328.

Suchentrunk F, Flux JEC, Flux MM, Ben Slimen H. 2007. Multivariate discrimination between east African cape hares (Lepus capensis) and savanna hares (L. victoriae) based on occipital bone shape. Mammalian Biology 72: 372-383.

Tamura K, Dudley J, Nei M, Kumar S. 2007. MEGA4: molecular evolutionary genetics analysis (MEGA) software version 4.0. Molecular Biology and Evolution 24: 1596-1599.

The IUCN Red List of Threatened Species. Version 2014.3. <www.iucnredlist.org>. Downloaded on 11 May 2015.

Thompson JD, Gibson TJ, Higgins DG. 2002. Multiple sequence alignment using ClustalW and ClustalX. Current Protocals in Bioinformatics Chapter 2: Unit 2.3.

Vial JL. 1962. The auditory bulla of Dipodomys deserti. (Rodentia) and evidence of its adaptive significance. Revista de Biologia Tropicale Costa Rica 10: 11-17.

Wible JR. 2007. On the cranial osteology of the Lagomorpha. Bulletin of Carnegie Museum of Natural History 39: 213234.

Williams SB, Wilson AM, Payne RC. 2007. Functional specialisation of the thoracic limb of the hare (Lepus europeus). Journal of Anatomy 210: 491-505.

Wu SY. 2003. The cranial morphology and phylogenetic relationship of Alloptox gobiensis (Lagomorpha, Ochotonidae). Vertebrata Palasiatica 41: 115-130.

Zelditch ML, Swiderski DL, Sheets HD, Fink WL. 2004. Geometric morphometrics for biologists: A primer. Elsevier academic press.

Zhang ZQ. 1997. The late Neogene Leporidae (Lagomorpha, Mammalian) from North China. PhD. dissertation.

Zhang ZQ. 2010. Revision of Chinese Pleistocene Lepus (Leporidae,Lagomorpha). Vertebrata Palasiatica 48: 262-274.

Received: 3 July 2014

Revised and accepted: 27 May 2015

Published online: 19 October 2015

Editor: A. Ivanović

\section{Online supplementary material}

S1. Phylogenetic tree file of extant Lagomorpha reconstructed from seven DNA fragments (Matthee et al., 2004). 


\section{Appendix 1}

Specimens studied in the present study

Brachylagus idahoensis (Merriam, 1891). MCZ: 34578.

Bunolagus monticularis (Thomas, 1903). MCZ: 56905.

Caprolagus hispidus (Pearson, 1839). FMNH: 30265; BMNH: 24.6.11.1.

Lepus americanus (Erxleben, 1777). ZISP: 86708, 78431, 129300, 5026; MSUM: 154722, 11187, 11189, 11190; ZMMSU: S40419.

Lepus californicus Gray, 1837. ZISP: 14463, 39399, 69575, 78624, 14464, 14462, 14465, 18276, 12329, 67740; MSUM: 116703, 136228.

Lepus tolai Pallas, 1778. IOZCAS: 26751, 26752; ZISP: 45366.

Lepus timidus Linnaeus, 1758. IOZCAS:3709, 3714, 3715, 26779, 26780, H03011, H03012, H03013, H03014.

Lepus townsendii Bachman, 1839. ZISP:12333, 124432.

Nesolagus timminsi Averianov, Abramov and Tikhonov, 2000. ZISP:84772.

Ochotona princeps (Richardson, 1828). MSUM: 65641, 8993, 60601, 65626,105455,105456.

Ochotona argentata Howell, 1928. IOZCAS: 30889.
Ochotona koslowi ((Büchner, 1894). NIPBCAS: 0006334.

Ochotona thomasi Argyropulo, 1948. IOZCAS: 25841. Oryctolagus cuniculus (Linnaeus, 1758). ZISP: 15125, 20833, 28454, 31826, 34164, 34285, 50603, 85791, 90178, IOZCAS: No number.

Pentalagus furnessi (Stone, 1900). ZISP: 15887.

Poelagus marjorita (St. Leger, 1929). AMNM: 51031, 51037, 51052, 51055, 51066, 118856; BMNH: 30.3.6.

Pronolagus crassicaudatus (I. Geoffroy, 1832). CZMHU: 17915; BMNH, 53.8.29.29.

Pronolagus randensis Jameson, 1907. CZMHU:33983. Pronolagus rupestris (A. Smith, 1834). FMNH: 177246.

Romerolagus diazi (Ferrari-Pérez, 1893). FMNH: 29831; CZMHU: 19784; BMNH: 842093.

Sylvilagus aquaticus (Bachman, 1837). ZISP: 85185.

Sylvilagus audubonii (Baird, 1858). MSUM: 116708, 116709, ZISP: 40069.

Sylvilagus floridanus (J.A. Allen, 1890). MSUM: 8552; 184891.

Sylvilagus floridanus (J.A. Allen, 1890). ZISP: 85189, 85190.

Sylvilagus nuttallii (Bachman, 1837). IOZCAS: 60X; MSUM: 65624; IOZCAS: B06, B07.

Sylvilagus palustris (Bachman, 1837). MSUM: 11185. 


\section{Appendix 2}

\section{Definition of landmarks}

\section{Dorsal cranium}

1. Anterior tip of nasal bone

2. Point of tangency along anterior lateral margin nasal bone

3. Meeting point between nasal bone and frontal bone along longitudinal axial of cranium

4. Posterior tip of suture between nasal bone and frontal bone

5. Anterior tip of zygomatic bone in the lateral edge

6. Anterior meeting point between zygomatic bone and frontal bone in the interior edge of orbit

7. Most lateral point along the interior edge of zygomatic bone

8. Most posterior point along the interior edge of zygomatic bone

9. Meeting point of frontal bone and parietal bone along longitudinal axial of cranium

10. Posterior meeting point of frontal bone and parietal bone

11. Meeting point of parietal bone and supraoccipital bone along longitudinal axial of cranium

12. Most posterior point of the supraoccipital bone along longitudinal axial of cranium

13. Most posterior point of parietal bone

14. Most lateral point of parietal bone

\section{Ventral cranium}

1. Meeting point of incisors

2. Lateral contact point of incisors and premaxilla

3. Anterior point of the incisive and palatal foramen along longitudinal axial of cranium

4. Meeting point of premaxilla and maxillary along the lateral edge of incisive and palatal foramen

5. Most anterior point of palatal bridge along the longitudinal axial of cranium

6. Posterior end of the incisive and palatal foramen

7. Most lateral tangent point of the incisive and palatal foramen

8. Anterior end of the cheek tooth row

9. Most posterior end point of palatal bridge along the longitudinal axial of cranium

10. Anterior end of palatal bridge along the lateral margin of entopterygoid crest

11. Anterior concave point of the zygomatic along the lateral margin

12. Posterior end of the cheek tooth row

13. Most anterior end of orbital

14. Most interior lateral end of orbit

15. Most posterior end of orbit

16. The tangent point where the posterior lateral margin of zygomatic expanded in the internal edge of orbit

17. The tangent point where the posterior lateral margin of zygomatic expanded in the lateral edge of orbit

18. Most anterior point of basioccipital bone along the longitudinal axial of cranium

19. Lateral end of basioccipital bone meeting with basisphenoid bone

20. Most anterior point of tympanic bulla

21. Lateral meeting point of tympanic bulla and basisphenoid bone

22. Most lateral expansion of tympanic bulla

23. Opening of external carotid artery

24. Most internal contraction of basioccipital bone along lateral margin

25. Most anterior end of foreman magnum

26. Most lateral end of foreman magnum

27. Most posterior end of foreman magnum

\section{Mandible}

1. Upper extreme anterior point of the incisor alveolar

2-3. Point of trisection between landmark 1 and landmark 4 along the upper contour of anterior veolar

4. Anterior end of tooth row

5. Posterior end of tooth row

6. Middle point between landmark 5 and landmark 7

7. The highest point of coronoid process

8. Middle point between landmark 7 and landmark 9

9. Anterior point of condylar process

10. Posterior point of condylar process

11-14. Quadrate points between landmark 10 and 14

14. Highest point of angular process

15-17. Quadrate points between landmark 14 and 18

18. Lowest point of angular process

19. Middle point on the lateral edge of mandibular body 
20-24. Landmarks between 19 and 25, which divided the lateral edge of posterior alveolar and incisor alveolar into six equal lengths

25. Lower extreme anterior point of the incisor alveolar

Upper edge along orbit

Landmark 6 and landmark 8 define the start point and end point of the curve, 48 landmarks were equally distributed along the curve by length. 